\title{
STUDY ON STATIC DEFLECTION OF FIBRE REINFORCED COMPOSITE PLATES USING MATLAB
}

\author{
Amitanand B Suralikerimath ${ }^{1}$, Yallanagouda I Ninganagoudar ${ }^{2}$, Nagesh R Naganur ${ }^{3}$ \\ ${ }^{1}$ Student, Department of Mechanical Engineering, Basaveshwar Engineering College, Karnataka, India \\ ${ }^{2}$ Student, Department of Mechanical Engineering, Basaveshwar Engineering College, Karnataka, India \\ ${ }^{3}$ Student, Department of Mechanical Engineering, Basaveshwar Engineering College, Karnataka, India
}

\begin{abstract}
In recent years composites are widely used in various engineering applications because of their high stiffness to weight ratio which makes them lighter materials. The understanding of the static behaviour of composites is necessary for the proper utilization, thus from literature study it is observed that static and dynamic analysis of composite structures is carried out by various researchers. The present work aims at studying the static deflection of composite structure using MATLAB by Finite Elements Method. A simply supported laminated composite plate with point load acting at its centre is considered for present formulation. The number of elements and nodes are increased and the results obtained are validated and compared.
\end{abstract}

Keywords: Composites, Static Deflection, MATLAB, Nodes.

\section{INTRODUCTUION}

The application of composite materials in various engineering and commercial sectors has led to increased interest in studying its properties, theory, analysis and design. From the literature survey it is imminent that efforts are being made to develop new composite systems, design and analyze it.

The static, dynamic and natural frequency analysis is important in designing of composite structures which are used in various engineering fields like aerospace, automotive, mechanical and civil etc. For a thorough study on its static and dynamic behavior appropriate composite models are developed. A considerable amount of research has been done in understanding static and dynamic behavior of laminated composite plates. Numerical tools have been considered as most effective for analysis.

The finite element method is considered to be most effective and successful approach for such problems. There is a vast amount of literature on static and dynamic analysis of laminated plates which is plethora to mention here.

The finite element method (FEM) is a numerical tool used to find approximate solutions to boundary value and Eigen value problems for partial differential equations. It is also referred to as finite element analysis (FEA). FEM divides a large problem into smaller, parts, called finite elements.

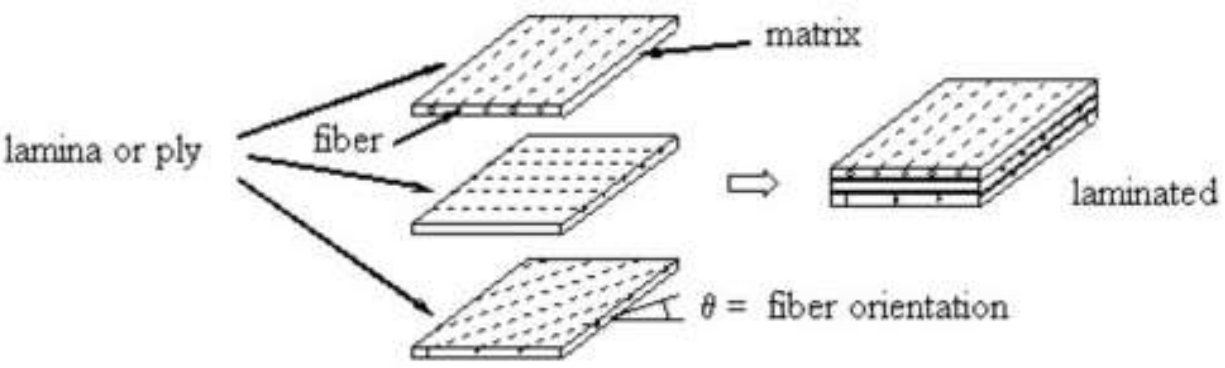

Figure 1. Laminated composite materials

R.R Bhat [1] has researched considerably on natural frequencies of rectangular plates using orthogonal polynomials in R-R method. He used different boundary conditions and compared natural frequencies for subsequent conditions. Srinivas [2] has researched on development of an accurate analysis method for static and dynamics of composite plates. Accuracy is determined by comparing free vibrations of simply supported laminates and then comparing them with 3-D analysis. J.N Reddy [3] studied on higher order shear deformation theory. He compared results of proposed theory with 3-D elastic solutions. His theory proved to be accurate and predicted exact deflections and stress. Stavsky Y [4] extended Mindling's theory [5] for homogenous isotropic plates to thick laminates consisting of an ordinary number of bonded anistropic layers. Whitney and J.N, Pagano [6] studied extensively on Shear Deformation in Heterogeneous anisotropic plates. 


\section{OBJECTIVES}

This paper concentrates on the static behavior of composite structure and to interpolate the static deflections by using MATLAB. The following objectives have to be met in sequel.

- Develop finite element model for static analysis of the composite plate.

- Study the static behavior of composite plates and compare the results by increasing the number of elements and nodes using MATLAB.

- Obtained results are validated with the existing data.

\section{PROPOSED METHEDOLOGY}

1. The developed finite element model is converted to MATLAB codes.

2. The MATLAB codes will be validated with the existing results.

3. The validated codes are used to study the static behavior by increasing the number of elements and nodes.

4. Obtained results are validated and compared for accuracy.

\section{PROBLEM SOLVING PROCEDURE}

Following is the procedure followed to obtain the static deflections in MATLAB.

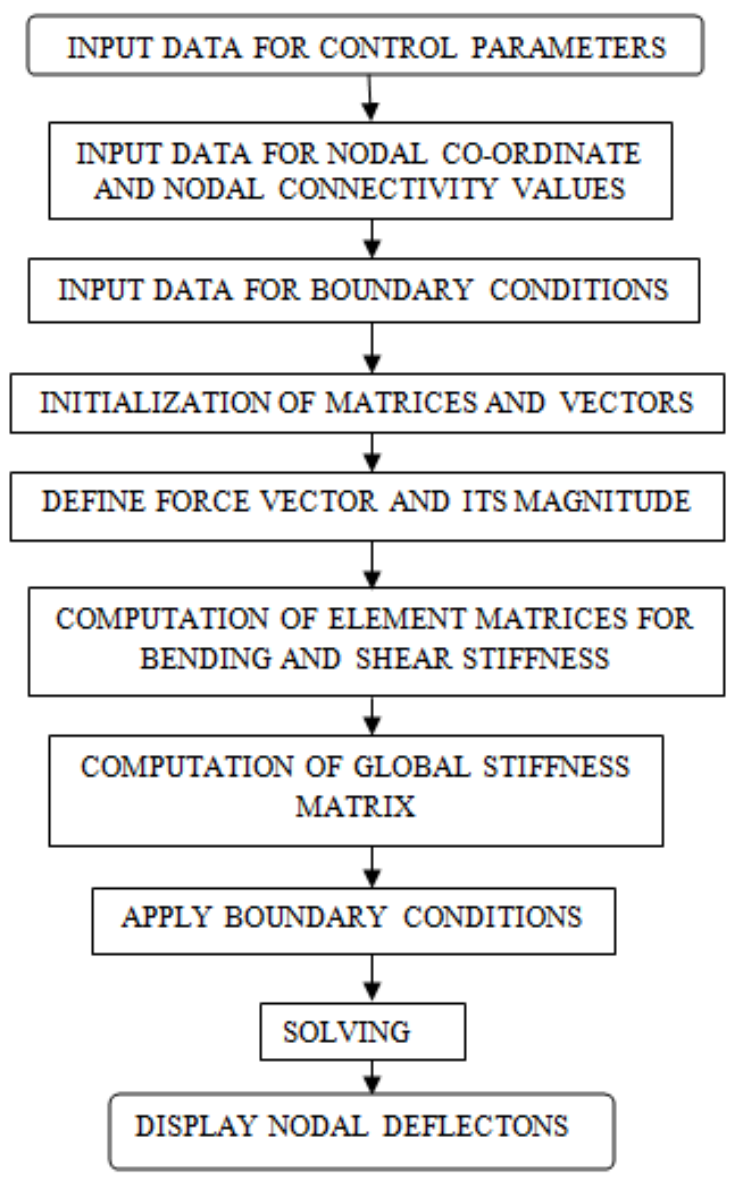

Fig-2 Problem Solving Procedure

\section{RESULTS AND DISSCUSSIONS}

This study considers the non dimensional central deflection response of laminated composite plates with simply supported boundary conditions. Material properties used are $\left[\mathrm{E}_{1} / \mathrm{E}_{2}=25, \mathrm{G}_{12}=\mathrm{G}_{13}=0.5, \mathrm{G}_{23}=0.2, \mathrm{v}_{12}=0.25\right]$. [7] The point load is applied at the centre of the plate and orientation considered here is $(0 / 90)$. The results are obtained for $2 \times 2$ and $4 \times 4$ models i.e. number of elements and nodes are increased. The variation of non-dimensional central deflection with increase in number of layers is also discussed here.

Table 1 validation of results obtained with JNR

\begin{tabular}{|l|l|l|l|l|l|}
\hline $\begin{array}{l}\text { Orientati } \\
\text { ons }\end{array}$ & JNR & $\mathbf{2 \times 2}$ & $\begin{array}{l}\text { \% } \\
\text { error }\end{array}$ & $\mathbf{4 \times 4}$ & $\begin{array}{l}\text { \% } \\
\text { error }\end{array}$ \\
\hline$(\mathbf{0 / 9 0 )}$ & 4.666 & 3.87 & 17 & 4.702 & 0.7 \\
\hline$(\mathbf{0 / 9 0})_{\mathbf{2}}$ & 2.2105 & 1.84 & 16.7 & 2.245 & 1.5 \\
\hline$(\mathbf{0 / 9 0})_{\mathbf{4}}$ & 1.9536 & 1.63 & 16.5 & 1.984 & 1.6 \\
\hline
\end{tabular}

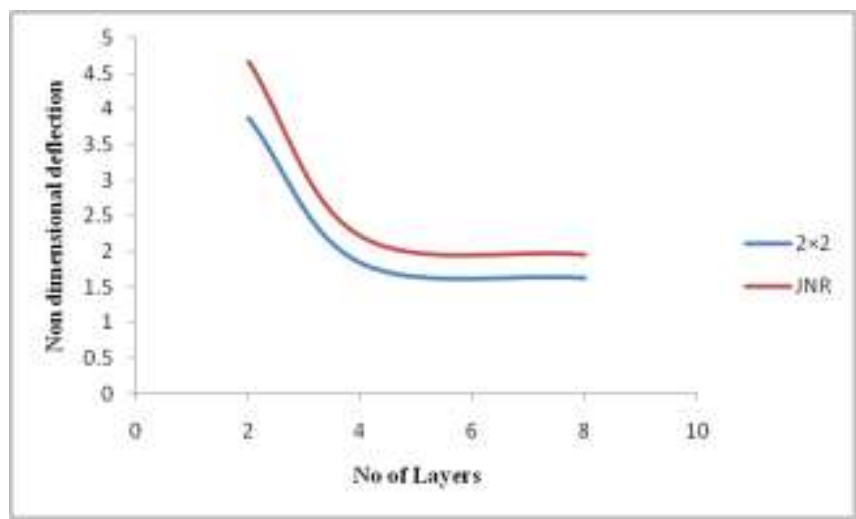

Graph1. Comparison of $2 \times 2$ model with JNR

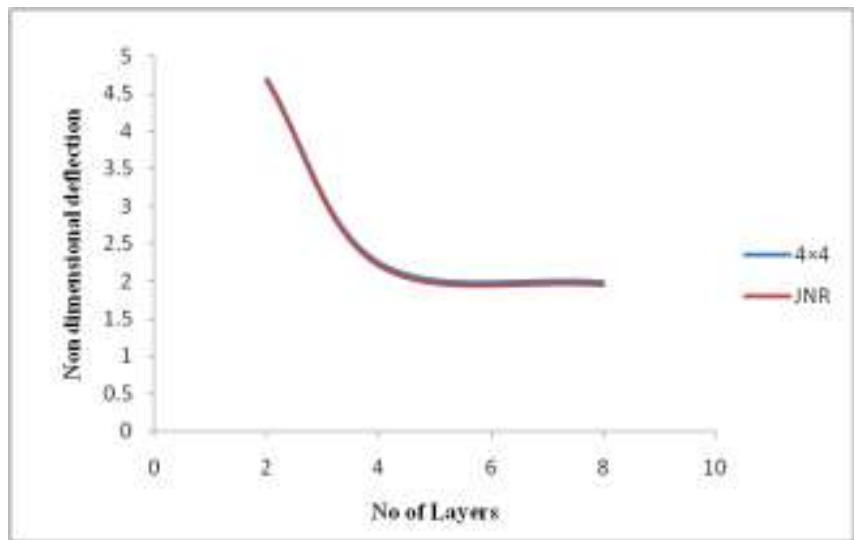

Graph2. Comparison of $4 \times 4$ model with JNR

\section{CONCLUSION}

The table of results is plotted for $(0 / 90)$ orientation with increase in number of layers and graphs are plotted for $2 \times 2$, $4 \times 4$ models with JNR by considering No of Layers on Xaxis and Non Dimensional central deflection on Y-axis.

- After validation of results with JNR the percentage error for $2 \times 2$ model is high as compared to $4 \times 4$ model. This is because the results obtained are more accurate 
for $4 \times 4$, since the number of elements and nodes increases.

- The value of central deflection keeps on decreasing as the number of layers increases because the value of bending stretching and coupling coefficients which make up [B] matrix decreases.

\section{REFERENCES}

[1]. Bhat, R.R, "Natural Frequencies of Rectangular Plates using Characteristic Orthogonal Polynomial in RayleighRitz method", Journal of Sound and Vibration, Vol. 102, 1985, pp.493-499.

[2]. Srinivas, "A refined analysis of composite laminates", Journal of Sound and Vibrations, Vol. 30, 1973, pp. 495507.

[3]. Reddy, J.N, "A simple higher order theory for Laminated composites", Journal of Applied Mechanics, Vol. 51, 1989, pp. 745.

[4]. Stavsky, Y, "On the Theory of the Symmetrically Heterogeneous Plates having the same thickness variation of the elastic moduli", Topics in Mechanics, 1965, pp.105.

[5]. Mindlin, R.D, "Influence of Rotary Inertia and Shear on Flexural Motions of Isotropic elastic Plates", Journal of Applied Mechanics, Vol. 18, 1951, pp. 31-38.

[6]. Whitney, J.N, Pagano, N.J, "Shear Deformation in Heterogeneous anisotropic plates", Journal of Applied Mechanics, Vol. 37, 1970, pp. 1031-1036.

[7]. J.N Reddy, Mechanics of Composite Materials and Shells Theory and Analysis.

\section{BIOGRAPHIES}

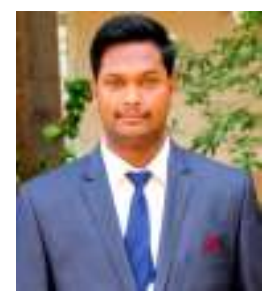

Amitanand B Suralikerimath is the first author studying in the final year of Bachelor of Engineering in Basaveshwar Engineering College, Bagalkot. His areas of interest are Solid Mechanics, Applied Mechanics, Composite Materials and Machine Design.

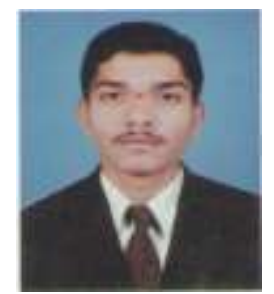

Yallangouda I Ninganagoudar is the second author studying in the final year of Bachelor of Engineering in Basaveshwar Engineering College, Bagalkot. His areas of interest are Strength of Materials and Machine Design.

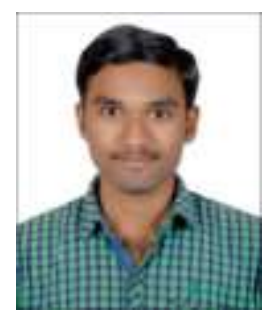

Nagesh $R$ Naganur is the corresponding author studying in the final year of Bachelor of Engineering in Basaveshwar Engineering College, Bagalkot. His areas of interest are Strength of Materials, Mechanical Vibrations, Fluid Mechanics and Thermodynamics. 